\title{
The inflluence of emulsifiers on physical properties and release parameters of creams with caffeine
}

\author{
Dorota Dwornicka, Katarzyna Wojciechowska, Maria Zun, \\ Regina Kasperek, Katarzyna Swiader, Michal Szumilo, Ewa Poleszak
}

Chair and Department of Applied Pharmacy, Medical University of Lublin, Chodźki 1, 20-093 Lublin, Poland

\section{ARTICLE INFO \\ Received 18 March 2015 \\ Accepted 30 April 2015}

\section{Keywords:}

caffeine release,

creams,

emulsifiers,

rheology.

\begin{abstract}
Caffeine is well known alkaloid chemical compound belonging to the methyl-xanthines group. It is an active substance that is found in many cosmetic products, as it has a stimulating action on both the central nervous system and the metabolism. Commercially available topical formulations normally contain 3\% of caffeine and $7 \%$ anticellulite products.

The aim of our work was to investigate the properties of four cream preparations. These consisted of $5 \%$ of caffeine and one of four different emulsifiers (GSC, Sodium polyacrylate, Emulsifying Base, MDS). In our work, we compared the physical properties (spreadability, slip and tenacity), the rheological structure of the resulting creams and the caffeine release from the obtained preparations. The results showed that the properties of these creams and their drug release depended upon the kind of the emulsifiers utilised. What is more, all preparations have a pseudoplastic character of flow and most of them have significant thixotropy. Furthermore, the amount of released caffeine is the largest from the MDS cream, and this emulsifier seems to be the most optimal in all the examined items.
\end{abstract}

\section{INTRODUCTION}

Caffeine, a tooted 'active ingredient', is one of the most common additives in many cosmetic products. It is also frequently used in skin penetration experiments as means of modeling the highly water-soluble compounds which are unchanged by occlusion and skin thickness $[12,16,17,18]$. This alkaloid belongs to the methyl-xanthines group, and it has demonstrated antioxidant and anti-inflammatory activities. It has been fully researched, and its purported properties include firming the skin, increasing its elasticity and decreasing the skin's cellulite content. Hence, caffeine is a key ingredient in anticellulite products because of its effect on adipocyte lipolysis through the inhibition of phosphoesterase and the stimulation of a high intracellular level of cAMP $[15,17]$. Caffeine also supposedly slows down lipogenesis and stimulates lipolysis in a variety of diverse ways [3]. What is more, many publications have shown the stimulating effect of topically applied caffeine complexes on hair growth. This is due to its effect on increasing hair fiber diameter $[5,10]$.

\footnotetext{
* Corresponding author

e-mail: dor.dwor@wp.pl
}

Beside the active substance, utilizing a suitable emulsifier is very important in the production of cosmetic creams. There are many synthetic and natural emulsifiers employed, but the choice of appropriate emulsifier is particularly very important in the production of biphasic cosmetics, as the chosen emulsifier can have a significant influence on the resulting preparation's physicochemical properties, stability and application values [2,14]. In the current literature, there is not a lot of information on this subject, thus, the aim of this study was to ascertain the properties of four creams containing $5 \%$ of caffeine, but based upon four different emulsifiers (GSC, Sodium polyacrylate, Emulsifying Base EB and MDS), by comparing and defining the influence of these emulsifiers on the physical properties, rheology and release parameters of the creams.

\section{MATERIALS AND METHODS}

\section{Chemicals}

Caffeine anhydrous was purchased from Sigma-Aldrich Chemie Gmbh, Germany. Methyl Glucose Sesquistearate (MDS), Glyceryl Stearate Citrate (GSC), Emulsifying Base 
(EB) and Sweet almond oil were acquired from Sigma SPA, IMCD, Warsaw. Cetyl alcohol was purchased from Galenic Laboratory, Olsztyn. The remaining utilized chemicals were produced by Avantor Performance Materials, Poland S.A.

\section{Apparatus}

Magnetic stirrer - Type MM 6; Mixer Cito-Unguator c/s - Eprus; Extensometer; Rheotest 2 viscometer - Medingen, Germany; Ultratermostat MLW UH 4-VEB MLW Medingen, Germany; Dialysis membrane - Visking ${ }^{\circledR}$ Serva; Spectrophotometer Helios Omega UV-Vis - SpectroLab, Poland; Paddle Apparatus Erweka DT-600 - Germany.

\section{Cream preparation}

The concentration of caffeine in all produced creams was $5 \%$. Four kinds of creams $(\mathrm{C} 1, \mathrm{C} 2, \mathrm{C} 3, \mathrm{C} 4)$ were prepared. Their composition is given in Table 1 .

The caffeine was dissolved in warm water (phase 1), while the cetyl alcohol, isopropyl myristate and the emulsifier were melted within warm Sweet almond oil (phase 2). After cooling, phase 2 was added to phase 1, and the resulting product was stirred to obtain a homogenous cream. All preparations were then additionally homogenized in the unguator, to obtain uniform consistency.

Table 1. Composition of the preparations

\begin{tabular}{|c|c|c|c|c|}
\hline ngredients & C1 & C2 & C3 & C4 \\
\hline Water & 75 & 75 & 75 & 75 \\
\hline Caffeine & 5 & 5 & 5 & 5 \\
\hline Cethylic alkohol & 2 & 2 & 2 & 2 \\
\hline Isopropyl myristate & 2 & 2 & 2 & 2 \\
\hline Sweet almand oil & 13 & 13 & 13 & 13 \\
\hline GSC & 3 & - & - & - \\
\hline Sodium polyacrylate & - & 3 & - & - \\
\hline EB & - & - & 3 & - \\
\hline MGS & - & - & - & 3 \\
\hline
\end{tabular}

GSC - Glyceryl Stearate Citrate; EB - Glyceryl Stearate, Cetyl alcohol, Stearic acid, Lauryl Sodium Glutamate; MGS - Methyl Glucose Sesquistearate

\section{The physical properties of creams}

Determination of the spreadability

The spreadability of each tested cream was measured in the extensometer at $20^{\circ} \mathrm{C} \pm 0.1^{\circ} \mathrm{C}[1,9]$. The relationship between the load added every 60 seconds and the stretched surface of the cream under test $\left(\mathrm{mm}^{2}\right)$, with the standard deviation (SD), is presented in Figure 1.

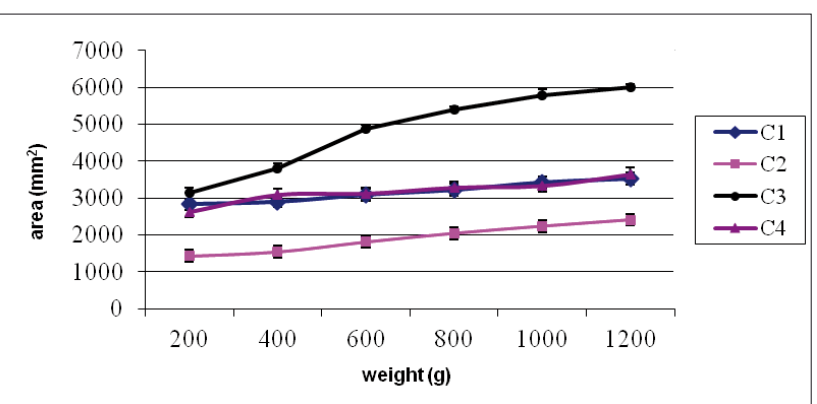

Figure 1. Spreadability of the creams C1, C2, C3, C4

\section{Determination of the slip}

The slip test measured the load that induced the movement of two plates separated by the cream that is under test. The average of three measurements per tested cream is showed in Figure 2.

\section{Determination of the tenacity}

The tenacity test was conducted in an apparatus set up according to the Münzel project [11]. This apparatus consists of two stainless steel plates of $27 \mathrm{~mm}$ diameter. On the lower stationary plate, an equal amount of cream was applied. This was then covered with the upper plate which was suspended by a string and attached to a balance dish. To this, $5 \mathrm{~g}$ of weight was added every 20 seconds until the top plate detached from the bottom plate. The averages of 6 measurements are presented in Figure 2.

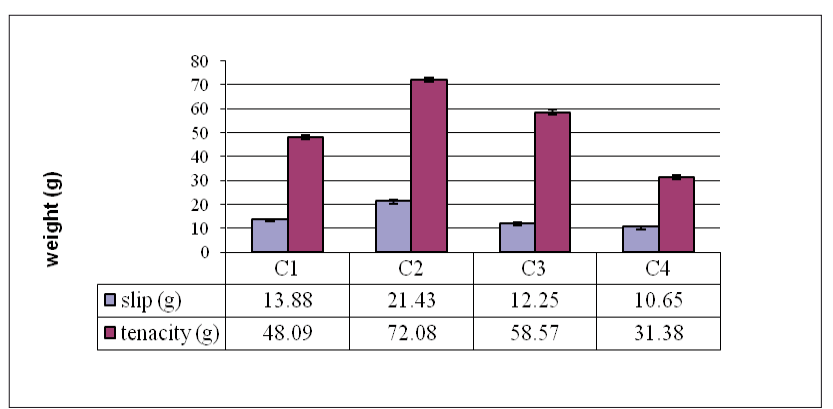

Figure 2. Slip and tenacity of the creams C1, C2, C3, C4

\section{Rheological studies}

Rheological studies are very important for the determination of the stability, the viscosity and the fluidity characteristics of creams. Moreover, such studies are important for ascertaining whether thixotropy appears. Furthermore, rheological studies enable the prediction of the behavior of the skin preparations during production, storage and use $[6,7,8]$.

Such measurements were performed after homogenization, by way of using a "Rheotest- 2 " with thermostat, at $20^{\circ} \mathrm{C}$ and $32^{\circ} \mathrm{C}$, and at a shear rate (Dr) between 1.5 to $656.0 \mathrm{~s}^{-1}$.

The relative viscosity coefficient $(\mathrm{k})$, power law index (n) and hysteresis loop area $\Delta \mathrm{H}$ were calculated using Ostwald de Waele's power-low model $\tau_{\mathrm{r}}=\mathrm{k} \cdot \mathrm{D}_{\mathrm{r}}^{\mathrm{n}}$. These are given in Table 2. The rheograms of each cream are presented in Figures 3,4.

Table 2. The calculated values of $\mathrm{n}, \mathrm{k}, \Delta \mathrm{H}$ for tested creams at 20 and $32^{\circ} \mathrm{C}$

\begin{tabular}{|c|c|c|c|c|c|}
\hline Temp. $\left({ }^{\circ} \mathrm{C}\right)$ & Const & $\mathrm{C} 1$ & $\mathrm{C} 2$ & $\mathrm{C} 3$ & $\mathrm{C} 4$ \\
\hline \multirow{3}{*}{$20^{\circ} \mathrm{C}$} & $\mathrm{k}$ & 152.24 & 547.25 & 213.94 & 174.3 \\
\cline { 2 - 6 } & $\mathrm{n}$ & 0.2965 & 0.0806 & 0.2257 & 0.2467 \\
\cline { 2 - 6 } & $\Delta \mathrm{H}$ & 34921.29 & 53763.42 & 12080.07 & 32576.75 \\
\hline \multirow{3}{*}{$32{ }^{\circ} \mathrm{C}$} & $\mathrm{k}$ & 83.08 & - & 126.12 & 131.54 \\
\cline { 2 - 6 } & $\mathrm{n}$ & 0.3322 & - & 0.2841 & 0.2904 \\
\cline { 2 - 7 } & $\Delta \mathrm{H}$ & 28974.34 & - & 16675.01 & 26419.39 \\
\hline
\end{tabular}

$\mathrm{k}$ - relative viscosity coefficient $(\mathrm{mPa} \cdot \mathrm{s}), \mathrm{n}$ - power low index, $\Delta \mathrm{H}$ - hysteresis loop area $(\mathrm{mPa} \cdot \mathrm{s})$ 


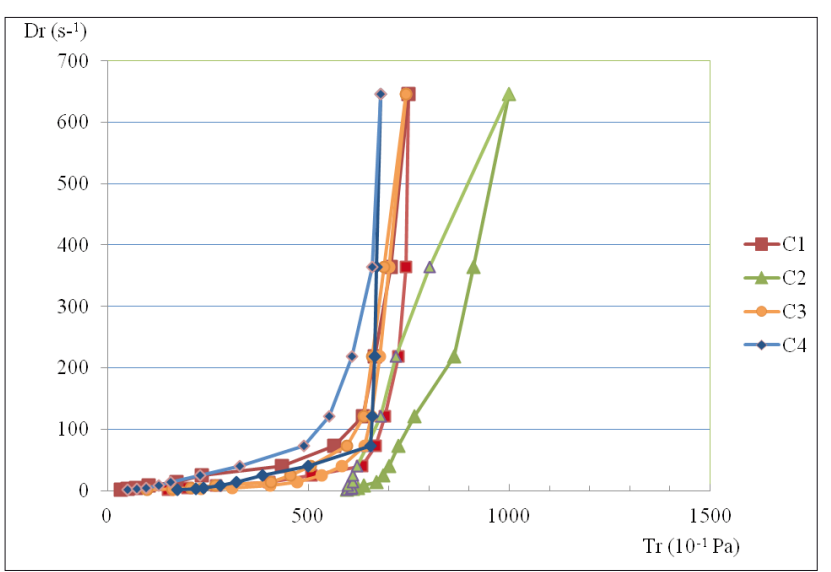

Figure 3. Rheograms of creams $\mathrm{C} 1, \mathrm{C} 2, \mathrm{C} 3, \mathrm{C} 4$, at $20^{\circ} \mathrm{C}$

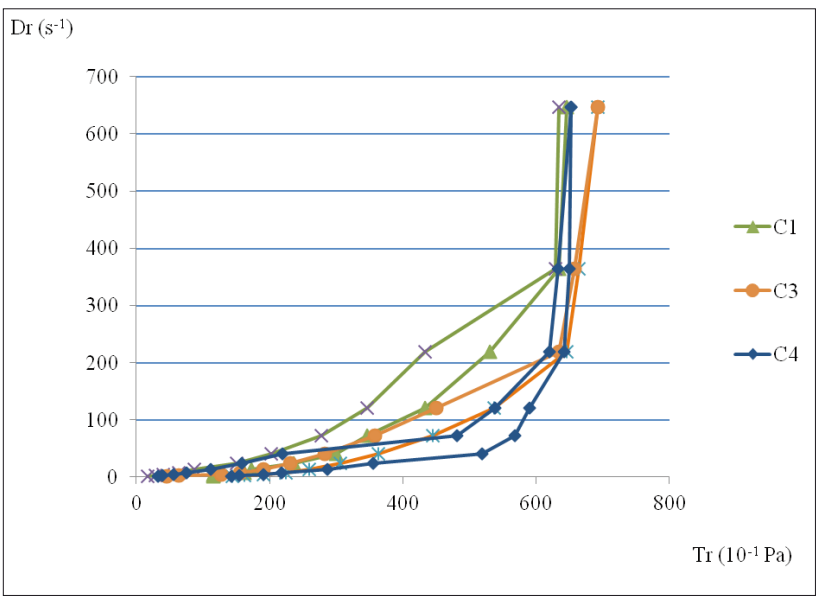

Figure 4. Rheograms of creams $\mathrm{C} 1, \mathrm{C} 3, \mathrm{C} 4$ at $32^{\circ} \mathrm{C}$

\section{Caffeine release studies}

The estimation of caffeine content

The quantitative analysis of caffeine was adopted from that set out in Polish Pharmacopeia IX. The UV spectrum analysis, as well as the calibration graph of caffeine was presented in a previous study [19]. For the estimation of caffeine content in the examined preparations, $1 \mathrm{~g}$ samples of each cream $\mathrm{C} 1, \mathrm{C} 2, \mathrm{C} 3$ or $\mathrm{C} 4$ were transferred into volumetric flasks, which were then completed with a phosphate buffer (pH 6.8 to $100 \mathrm{ml}$ ). Subsequently, $10 \mathrm{ml}$ of each solution was diluted to $100 \mathrm{ml}$ with the same buffer, and the caffeine content was determined against a blank of phosphate buffer ( $\mathrm{pH} 6.8$ at $273 \mathrm{~nm}$ ). The blank basis (without caffeine) showed no absorbance. The measurements were repeated three times. The results are given in Table 3 .

Table 3. The estimation of caffeine content in preparations $\mathrm{C} 1$, $\mathrm{C} 2, \mathrm{C} 3, \mathrm{C} 4$

\begin{tabular}{|c|c|c|c|c|}
\hline Preparation & $\begin{array}{c}\text { Content } \\
(\mu \mathrm{g} / \mathrm{ml})\end{array}$ & $\pm S D$ & \pm RSD \% & $\begin{array}{c}\text { Recovery } \\
(\%)\end{array}$ \\
\hline C1 & 25.06 & 1.48 & 5.91 & 100.23 \\
\hline C2 & 25.14 & 0.44 & 1.77 & 100.56 \\
\hline C3 & 25.21 & 0.21 & 0.84 & 100.83 \\
\hline C4 & 25.28 & 0.22 & 0.87 & 101.12 \\
\hline
\end{tabular}

$\mathrm{SD}$ - standard deviation, RSD - relative standard deviation

\section{Caffeine release}

Caffeine release studies were conducted by way of employing the dialysis method, in an extraction chamber, and through utilizing a Paddle Apparatus [4,13] (the speed rate of the paddle being $75 \mathrm{rpm})$. This was done in the presence of a phosphate buffer $\left(\mathrm{pH} 6.8\right.$ at $32^{\circ} \mathrm{C} \pm$ $1^{\circ} \mathrm{C}$ ). In the study, $2 \mathrm{~g}$ of each cream was weighed into the extraction chamber. The releasing was conducted after hydration utilizing an acceptor solution, through a dialysis membrane (Visking ${ }^{\circledR}$ Serva, with a pore diameter of $0.45 \mu \mathrm{m})$. Subsequently, $5 \mathrm{ml}$ samples were taken after 15 , $30,60,120,180 \mathrm{~min}$, and the remainder was completed with the phosphate buffer to the initial volume. Caffeine release was estimated spectrophotometrically at $273 \mathrm{~nm}$, and the caffeine concentration was calculated from the regression equation (taking into account the dilution). The results are presented as the average of five measurements, in Figure 5.

\section{RESULTS AND DISCUSSION}

Four preparations $(\mathrm{C} 1, \mathrm{C} 2, \mathrm{C} 3, \mathrm{C} 4)$ containing $5 \%$ of caffeine, sweet almond oil and one of the four emulsifiers (GSC, Sodium polyacrylate, EB, MGS) were prepared.

In the organoleptic estimation, all preparations were found to be homogenous. They had a white color and had no odour. After skin application, they were found to lubricate and to be absorbed very well.

The spreadability tests (Fig.1) show that the cream preparation consisting of the emulsifying base EB (C3) has the best spreadability (which was from about $3000 \mathrm{~mm}^{2}$ at a $200 \mathrm{~g}$ load, to $5987 \mathrm{~mm}^{2} \pm 64.76 \mathrm{~mm}^{2}$ at a $1200 \mathrm{~g}$ load). Within this parameter, sodium polyacrylate (C2) based cream has the worst (at a $1200 \mathrm{~g}$ load, the surface was $2403.50 \mathrm{~mm}^{2} \pm 41.08 \mathrm{~mm}^{2}$ ). The other creams (C1 and C4) have a similar spreadability $\left(3523.86 \mathrm{~mm}^{2} \pm 85.89 \mathrm{~mm}^{2}\right.$ for $\mathrm{C} 1$ and $3647.66 \mathrm{~mm}^{2} \pm 25.26 \mathrm{~mm}^{2}$ for $\left.\mathrm{C} 4\right)$. These results did not depend on load. Moreover, changes of spreadability in these creams are not significant.

The results of the slip tests (Fig. 2) show that creams C1, C3, C4 are similar: $10.65 \mathrm{~g} \pm 0.11 \mathrm{~g}-13.88 \mathrm{~g} \pm 0.04 \mathrm{~g}$, while cream $\mathrm{C} 2$ has the worst slip parameters $-21.43 \mathrm{~g} \pm 0.67 \mathrm{~g}$.

The best tenacity (Fig.2) was evidenced in cream C2 $72.08 \mathrm{~g} \pm 2.84 \mathrm{~g}$. The other results regarding this attribute are: $\mathrm{C} 3-58.57 \mathrm{~g} \pm 2.93 \mathrm{~g}, \mathrm{C} 1-48.09 \mathrm{~g} \pm 3.06 \mathrm{~g}, \mathrm{C} 4-31.38 \mathrm{~g}$ $\pm 1.58 \mathrm{~g}$.

The rheological studies reveal that all creams, but $\mathrm{C} 2$, have a pseudoplastic character of flowing at $20^{\circ} \mathrm{C}$ and $32^{\circ} \mathrm{C}$ (Fig. 3,4), according to the Oswald de Waele's power law model. Regarding cream $\mathrm{C} 2$, at $32^{\circ} \mathrm{C}$, in this case, the several attempts of carrying out the measurements have failed. The power low index (n) for all preparations was $0.0806-0.2965$ at $20^{\circ} \mathrm{C}$, and $0.2841-0.3322$ at $32^{\circ} \mathrm{C}$. The viscosity of the creams at the shear rate $\mathrm{Dr}=24.3 \mathrm{~s}^{-1}$, at $20^{\circ} \mathrm{C}$ was $2089.55 \mathrm{mPa} \cdot \mathrm{s}$ for $\mathrm{C} 1,2825.64 \mathrm{mPa} \cdot \mathrm{s}$ for $\mathrm{C} 2$, $2192.44 \mathrm{mPa} \cdot \mathrm{s}$ for $\mathrm{C} 3$ and $1590.91 \mathrm{mPa} \cdot \mathrm{s}$ for $\mathrm{C} 4$. At $32^{\circ} \mathrm{C}$, the results were, respectively, $973.54 \mathrm{mPa} \cdot \mathrm{s}$ for $\mathrm{C} 1,1258.48$ $\mathrm{mPa} \cdot \mathrm{s}$ for $\mathrm{C} 3$ and $1464.27 \mathrm{mPa} \cdot \mathrm{s}$ for $\mathrm{C} 4$. All the creams, at both temperatures, showed a thixotropy. At $20^{\circ} \mathrm{C}$, the highest hysteresis loop area $(\Delta \mathrm{H})$ was seen for cream $\mathrm{C} 2$ (53763.42 $\mathrm{mPa} \cdot \mathrm{s})$, and the lowest was seen for cream 
C3 (12080.07 mPa.s). The creams C1 and C4 had a similar thixotropy (respectively, $34921.29 \mathrm{mPa} \cdot \mathrm{s}$ and 32576.75 $\mathrm{mPa} \cdot \mathrm{s})$. At $32^{\circ} \mathrm{C}$, the size of thixotropy was smaller. At this temperature, the hysteresis loop area $(\Delta \mathrm{H})$ was similar for creams C1 and C4 (respectively, $28974.34 \mathrm{mPa} \cdot \mathrm{s}$ and $26419.39 \mathrm{mPa} \cdot \mathrm{s})$, and, regarding this parameter, the lowest value was seen for cream C3 (16675.01 $\mathrm{mPa} \cdot \mathrm{s}$ ) (Tab. 2).

The quantitative analysis of caffeine was undertaken according to Polish Pharmacopeia IX. The selectivity and the precision of the employed method for the analysis of caffeine in the subject creams are described in a previous study [19]. The same method was applied for the determination of caffeine content in all the prepared creams. This showed that the drug content in the preparations was found to be: $5.01 \% \pm 5.91 \%$ (RSD) for $\mathrm{C} 1,5.03 \% \pm 1.77 \%$ (RSD) for $\mathrm{C} 2,5.04 \% \pm 0.84 \%$ (RSD) for $\mathrm{C} 3$, and $5.06 \% \pm 0.87 \%$ (RSD) for C4 (Tab. 3). The accuracy of this method was confirmed by way of Student's t-test.

The release studies showed that after $180 \mathrm{~min}$., the best caffeine release was achieved from the cream with MGS as the emulsifier (C4): $74.05 \% \pm 1.76 \%$ (SD), and the worst was seen from the cream with EB as the emulsifier (C3): $45.49 \% \pm 1.45 \%$ (SD). The drug released in the other creams were, respectively: $66.63 \% \pm 0.51 \%$ (SD) for the GSC-based cream $(\mathrm{C} 1)$ and $65.40 \% \pm 0.80 \%(\mathrm{SD})$ for the sodium polyacrylate-based cream (C2). All the results are presented in Figure 5.

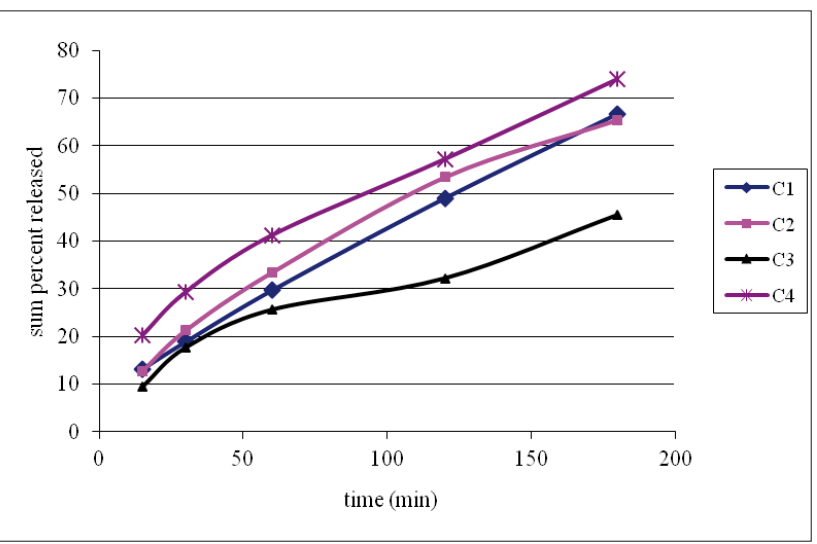

Figure 5. Caffeine release from the creams C1, C2, C3, C4

\section{CONCLUSIONS}

The results show that the physical properties and the drug release depend on the kind of emulsifier utilized. The best physical parameters were obtained for the cream based upon EB as the emulsifier (C3), but the amount of the released caffeine was the worst in this case, while the best caffeine release was achieved from the MGS-based cream (C4). All the preparations had a pseudoplastic character of flowing, while the thixotropy was significant in preparations $\mathrm{C} 2, \mathrm{C} 1$ and $\mathrm{C} 4$ at $20^{\circ} \mathrm{C}$, and $\mathrm{C} 1$ and $\mathrm{C} 4$ at $32^{\circ} \mathrm{C}$. Taking into account all the results, we can conclude that cream $\mathrm{C} 4$ has the most optimal properties. Thus, MGS (Methyl Glucose Sesquistearate) was seen to be the best of all examined emulsifiers.

\section{REFERENCES}

1. Achim M. et al:: Topical dosage forms containing fluid-extract of ruscus aculeatus: Formulation, preparation and physical characterization. Clujul Medical. 83, 99-103, 2010.

2. Ballman C., Mueller B.: Stabilizing effect of cetostearyl alcohol and glyceryl monostearate as co-emulsifiers on hydrocarbon-free $\mathrm{o} / \mathrm{w}$ glyceride creams. Pharm. Dev. Technol., 13, 433-445, 2008.

3. Barel A., Paye M., Maibach H.: Handbook of Cosmetic Science and Technology. Informa Health Care, New York, 2009.

4. Bottari F.: Influence of drug concentration on in vitro release of salicylic acid from ointment bases. J. Pharm. Sci., 63, 1979-1983, 1974.

5. Davis M.G. et al.: A novel cosmetic approach to treat thinning hair. Brit.J.Derm.,65, 24-30, 2011.

6. Erös I., Thaleb A.: Rheological studies of creams. I. Rheological functions and structure of creams. Acta Pharm. Hung., 64, 101-103, 1994.

7. Erös I., Thaleb A.: Rheological studies of creams. II. Effect of water content on rheological characteristics. Acta Pharm. Hung., 66, 71-76, 1996.

8. Erös I., Thaleb A.: Rheological studies of creams. III. Effect of lipophilic phase on consistency. Acta Pharm. Hung., 66, 77-81, 1996.

9. Fiebig A., Janicki St., Sznitowska M.: Farmacja stosowana. PZWL, Warszawa, 2004.

10. Fischer T.W.,Hipler U.C., Elsner P.: Effect of caffeine and testosterone on the proliferation of human hair follicles in vitro. Int. J. Derm., 46, 27-35, 2007.

11. Krówczyński L.: Technologia postaci leków. PZWL, Warszawa, 1969.

12. Otberg N. et al.: The role of hair follicles in the percutaneous absorption of caffeine. Br. J. Clin. Pharmacol., 65, 488-492, 2008.

13. Polish Pharmacopea IX, Urząd Rejestracji Produktów Leczniczych, Wyrobów Medycznych I Produktów Bójczych, Warszawa, 2011.

14. Provost C., Kinget R., Herbots H.: The influence of emulsifiers on drug diffusion from o/w cream. Pharm. Weekbl. Sci., 18, 248-251, 1981.

15. Roure R. et al.: Evaluation of the efficacy of a topical cosmetic slimming product combining tetrahydroxypropyl ethylenediamine, caffeine, carnitine, forskolin and retinol, in vitro, ex vivo and in vivo studies. Int. J. Cosm. Sci., 33, 519-526, 2011.

16. Sainio E., Rantanen T.,Kanerva L.: Ingredients and safety of cellulite creams. Eur. J. Dermatol., 10, 596-603, 2000.

17. Vogelgesang B. et al.: In vitro and in vivo efficacy of sulfo-carrabiose, a sugar-based cosmetic ingredient with anti-cellulite properties. Int. J. Cosm. Sci., 33, 120-125, 2011.

18. Wilkinson S.C. et al.: Interactions of skin thickness and physiochemical properties of test compounds in percutaneous penetration studies. Int. Archiv. Occup. Envir Health., 79, 05-413, 2006.

19. Wojciechowska K. et al.: Physical properties and caffeine release from creams prepared with different oils. Curr. Issues Pharm. Med. Sci., 27, 224-228, 2014. 